and besides we do not know if these are kings of Ceylon or only of Mâgama."

In het algemeen bericht over de inscripties der $10^{\text {de en }} 11$ de eeuw toont de uitgever in 't breede aan dat de koningsnamen van 'dat tijdperk doorgaans anders zijn dan die welke in den Mahâwansa opgegeven worden, zoodat het soms moeielijk is te ontdekken welke koning bedoeld is. Niet alleen 't verschil in namen, maar ook dat in de voorstelling der feiten baart moeielijkheden, zoodat men meermalen niet meer weet welke van beide autoriteiten te moeten gelooven, de inscriptie of de kronieken. Niet het minst zonderling is het feit dat de koning, die de talrijkste en langste opschriften, over 't geheele eiland verspreid, heeft nagelaten, namelijk Niççanka Malla, anders geheeten Kîrti Niççanka, die van 1187-1196 heerschte, in den Mahâvansa in tien regels wordt afgedaan, terwijl hij in de opschriften allerlei grootsche daden, veroveringen en anderszins, van zich zelven verkondigt, daden voor een deel overeenkomende met die welke in de kroniek aan zijnen voorganger Parâkrama-Bâhu I worden toegeschreven. Van Parâkrama-Bâhu is tot nog toe slechts éne grooter inscriptie, te Polonnaruwa of Pulastinagara, gevonden, waarin zijne maatregelen om de eendracht in de Buddhistische Kerk van Ceilon te herstellen beschreven worden. Het moet erkend worden dat dit belangrijke stuk ten volle bevestigt wat de Mahâwansa over die verdienstelijke daad van den koning bericht. Aangezien gezegde kroniek niet zoozeer eene geschiedenis van Ceilon, als wel van de lotgevallen der Buddhistische Kerk op het eiland is, laat zich de overeenstemming der twee autoriteiten in dit geval licht verklaren, te meer daar Parâkrama-Bâhu juist die partij begunstigde waartoe de opstellers van den Mahâwansa behoorden.

Zoo de historische waarde der inscripties niet zoo groot is als men had mogen verwachten, voor de geschiedenis van het Singhaleesch of Elu leveren ze onwaardeerbare bijdragen. Opmerkelijk is het dat geen enkel opschrift opgesteld is in het Pâli, de heilige taal der Zuidelijke Buddhisten, terwijl toch in Burma o. a. de groote inscriptie van Kalyâni geheel en al in 't Pâli vervaardigd is. Geheele stukken in 't Sanskrit zijn er op Ceilon evenmin; wel treft men in de opschriften van Niççanka Malla eenige verzen in onbeholpen Sanskrit aan. Hoe geheel anders is dat in Cambodja en op Java, waar gansche gedichten in een onberispelijk Sanskrit voorkomen. Doch de Indische 
invloed in deze twee laatste landen was dan ook van de brahmanen uitgegaan, en die waren even geleerd als de Buddhisti sche monniken onwetend.

Eene korte, maar niet onbelangrijke inscriptie, $\mathrm{N}^{0} .57$, is in een eenigszins afwijkend dialect geschreven. Ik houd den tekst voor oorspronkelijk Mâgadhî, waarin Singhalismen (niet-geaspireerden in plaats van aspiraten) ingeslopen zijn. Aan den rhythmus en de woordschikking is te merken dat het geschrift samengeflanst is uit brokstukken van verzen. Veronderstel dat de persoon van wien 't geschrift is, van eenige in Mâgadhî gedichte verzen, zooveel als hij van buiten kende of noodig oordeelde, te pas bracht; dan zouden de Singhalismen zich laten verklaren. Naar het mij toeschijnt, laat zich het facsimile aldus lezen :

"Siddham. Aparimite lokehi (of: loke hi) Budhasame nati acane parimaṇdale sawanyutopete anutare sathe mahasarane lakicake Budhaṇami (l. `nâmâ?) saya(m)bhu me galahi wihare Nakadewa (?) nâma Budhasaranagate mițhiyadiṭika 1 biṃdiya...... niyate."

"Heil! In de onbegrensde wereld is er geen gelijke van den Buddha. Onbeneveld 2 , overal rond, met alwetendheid begaafd, een weêrgalooze meester, mijn groote toevlucht is de glanskringige (of: de schijf van glans) die Buddha genaamd wordt, uit zich zelf geboren. In het klooster Gala (?) beveelt zich Nakadewa (?) in de hoede van Buddha aan. Moge Hij degenen die dwaalbegrippen aankleven vernietigen..... geschonken."

Wie zijn oogen niet willens en wetens voor 't licht der rede sluit, ziet hoe in den Buddha van deze inscriptie, welke Dr. Müller, mijns inziens te recht, niet later stelt dan in de eerste eeuw onzer jaartelling, het karakter van den Zonnegod doorschemert.

${ }^{1}$ Er staat volkomen duidelijk miţhya, doch het puntje in de letter kan licht uitgesleten of over 't hoofd gezien zijn; het behoorde te zijn mithiya. Miciya in Müller's transcriptie is een onmogelijk woord, daar Pâli micchâ zijne $c h$ uitsluitend te danken heeft aan de omstandigheid dat th door de onmiddellijk volgende $y$ gepalataliseerd is; in mithiy a volgt de $y$ niet onmiddellijk.

${ }^{2}$ Skr. achanna, synoniem met Pali wiwattacchadda. Natuurlijk zijn beide woorden oorspronkelijk een epitheton van de onbenevelde zon. Karakteristiek is de verdraaiing der beteekenis door de Buddhistische monniken, overgenomen door Childers: "One by whom the veil (of human passion) is rolled away." 


\section{PÜGAWAT OF PUTJANGAN.}

(Mededeeling VAN DR. H. VAN DER TuUk.)

Naar aanleiding van mịne vraag, in het opstel over de inscriptie van Er-Langa, van welken inlandschen plaatsnaam 't Skr. Pûgawat eene vertaling zou wezen, krijg ik van Dr. v. d. Tuuk de volgende inlichtingen. "Uw Pûgawat", schrijft hịj, "is uit de Pandjiromans bekend onder den naam van Putjangan, genoemd als de kluis van eene ongetrouwde vorstin vạ Koripan. In de Wajangverhalen door Roorda uitgegeven, bl. 210, zult gij Kĕputjangan vinden."

H. Kern. 


\section{N H 0 U D.}

Bladzijde.

Naamlijst der Leden van het Instituut . . . . . .

Lijst der binnen- en buitenlandsche aeademiën, geleerde genootschappen en instellingen, waarmede het Koninklijk Instituut door ruiling der uitgegeven werken in verbinding is . . . . . . . . . . . $\mathrm{xrV}$

250ste Bestuursvergadering, 15 Maart 1884 . . . . xvI

251ste Bestuursvergadering, 19 April 1884 . . . . $\mathrm{xx}$

252ste Bestuursvergadering, 17 Mei 1884 . . . . . xxv

253ste Bestuursvergadering, 21 Juni 1884. . . . . $\mathrm{xxx}$

254ste Bestuursvergadering, 20 September 1884 . . . xxxix

255ste Bestuursvergadering, 18 October 1884. . . . XLIV

256ste Bestuursvergadering, 15 November 1884 . . . XLVIII

Verslag van den staat en de werkzaamheden van het

Instituut over 1884 . . . . . . . . . . . . . $\quad$ LV

257ste Bestuursvergadering, 20 December 1884 . . . LXIX 258ste Bestuursvergadering, 17 Januari 1885 . . . . LXxIII

Sanskrit-inscriptie ter eere van den Javaanschen vorst

Er-Langa. Door Prof. Dr. H. Kern. . . . . . .

De herhaling met verandering van klinkers in het Soen-

daneesch. Door S. Coolsma . . . . . . . .

Lioe a Sin van Mandohr. Door Dr. J. J. M. de Groot

Beschrijving van het landschap Toebaroe of Gam-mieë.

Door C. F. H. Campen, Officier der Infanterie. Met eene kaart . . . . . . . . . . . . . . .

Eene bijdrage tot de kennis van 't oude Philippijnsche letterschrift. Door Prof. Dr. H. Kern . . . . . .

Reizen van D. F. van Braam Morris naar de Noordkust van Nederlandsch Nieuw-Guinea. Eerste vaart op de Amberno- of Rochussen-rivier. Medegedeeld door P. J. B. C. Robidé van der Aa. (Met twee kaarten) Nog iets over Javaansche inscriptiën. Door H. C. Humme

Een woord over de recensie van de vertaling der Abiåså.

Door H. C. Humme . . . . . . . . . . . . 
Verbeteringen in het artikel des Heeren C. F. H. Campen : „Eenige mededeelingen over de Alfoeren van Halema-héra'. . . . . . . . . . . . . . .

Sanskrit-inscriptie van Java, van den jare 654 Çaka. (A. D. 732). Door Prof. Dr. H. Kern (Met eene plaat) Uit de laatste dagen der Ned. Oostindische Compagnie. Mededeeling van B. W. Wttewaal van Wickerburgh

De besnijdenis bij de volken van den Indischen Archipel. Door Prof. Dr. G. A. Wilken . . . . . . .

De geschiedenis van Soetan Manangkérang. Een Maleische legende. Door J. L. van den Toorn . . .

- $-\ldots-$ - II. Vertaling en aanteekeningen III. Verklaringen .

Weder eene Javaansche isseriptie op Sumatra. Door H. C. Humme

Nog iets over "Gyanmigneranay." Door H. C. Humme. 370

Eene bijdrage over den feitelijken toestand der bevolking in de Lampongsche districten. Rangen en waardigheden, uitspanningen en kleeding, godsdienst, huwelijk en de positie der vrouw. Door G. J. Harrebomée, Contrôleur der eerste klasse . . . . . . . .

De Sulaneezen, hunne gebruiken bij huwelijken, geboorte en bij het mutileeren des lichaams. Door J. G. F. Riedel . . . . . . . . . . . . .

Eenige opmerkingen naar aanleiding eener eritiek van van mijn "Matriarchaat bij de oude Arabieren" Door Prof. Dr. G. A. Wilken . . . . . . . . . .

Boegineesche en Makassaarsche legenden. Door Dr. B. F. Matthes . . . . . . . . . . . . . . .

De oorsprong en de vestiging der Boalemoërs op NoordSelebes. Door J. G. F. Riedel

Het Sanskritopsehrift te Bekasih. Door Prof. Dr. H. Kern De betrekkingen tusschen Achter-Indië en Indonesië. Door Prof. Dr. H. Kern . . . . . . . . .

Geschied- en oudheidkundige nasporingen in Britsch Burma. Door Prof. Dr. H. Kern . . . . . . . Een werk over oude opschriften van Ceilon. Door Prof. Dr. H. Kern . . . . . . . . . . . . . .

Pûgawat of Putjangan. (Mededeeling van Dr. H. van der Tuuk) 


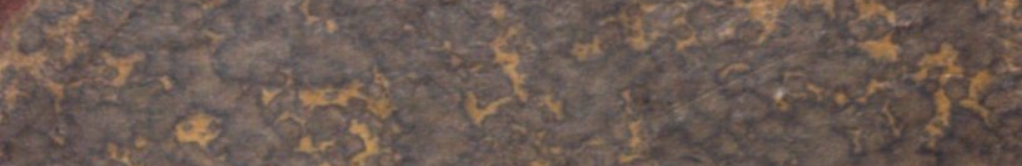

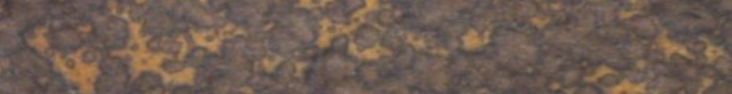

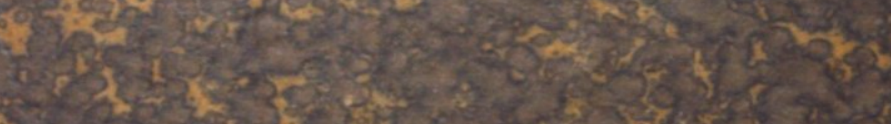

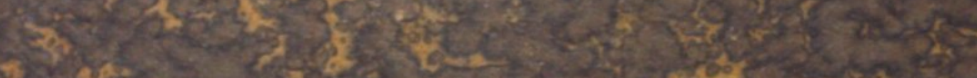

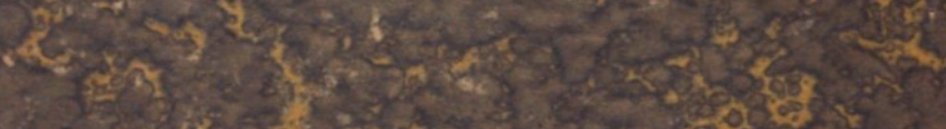

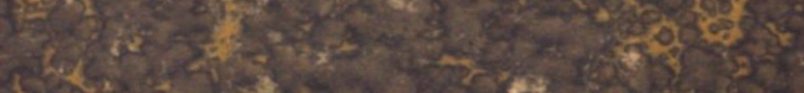

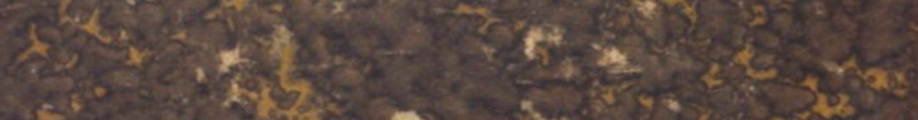

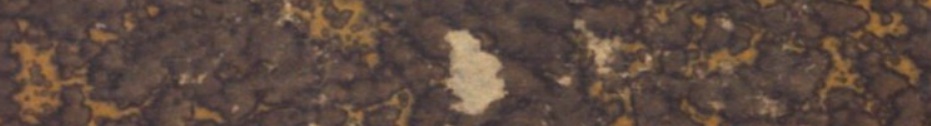
$30=20$.

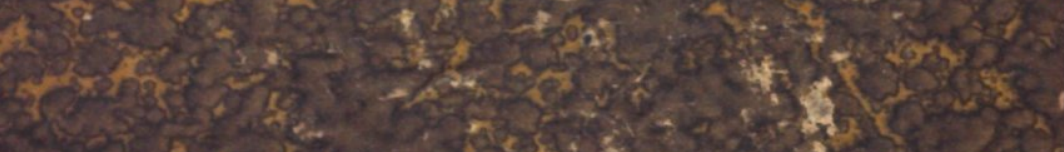

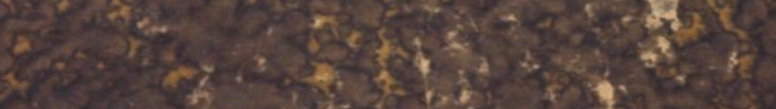

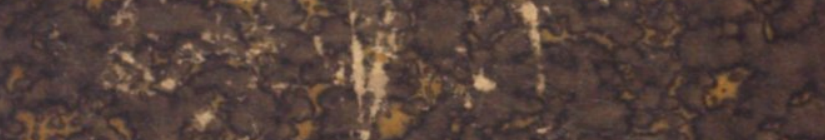

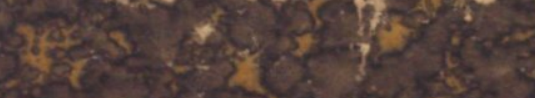

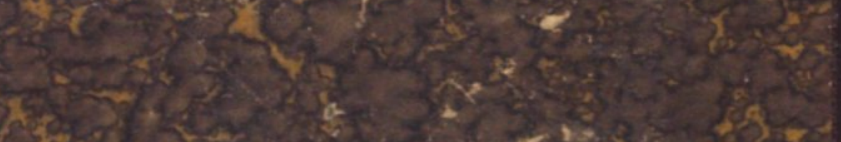

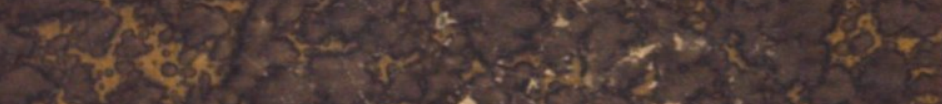

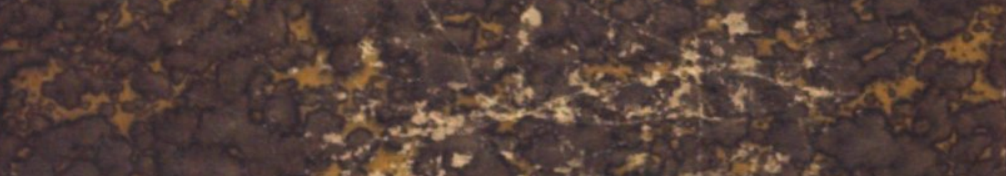

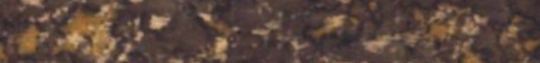

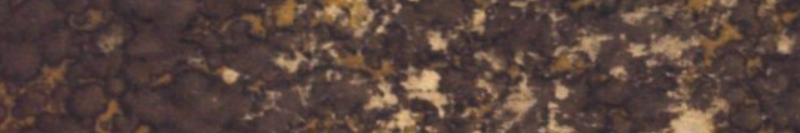

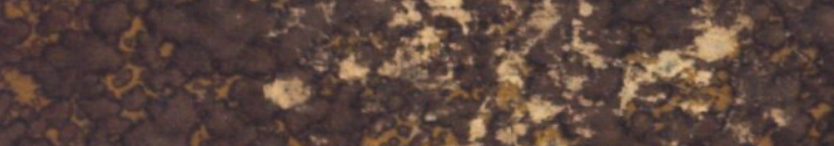

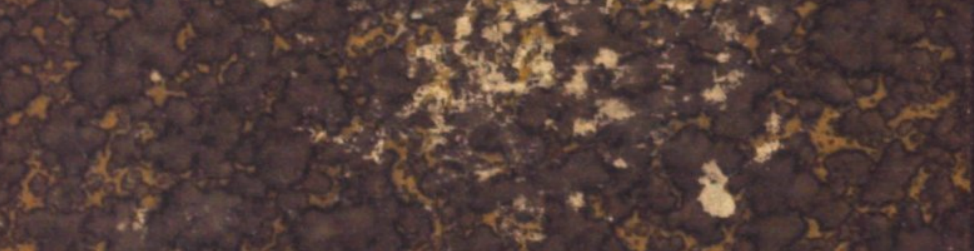

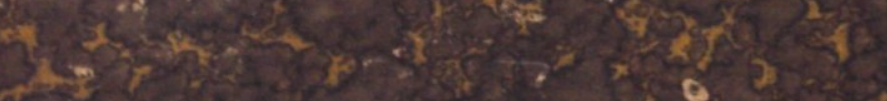
30

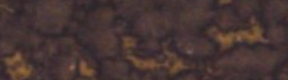

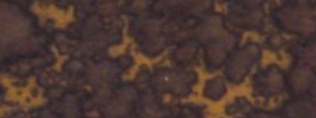
$-40003$
460 ing 